\title{
As novas tecnologias da informação e comunicação na perspectiva do ensino de Geografia
}

\author{
Daniel de Brito Ricarte \\ Ana Beatriz Gomes Carvalho
}

SOUSA, RP., MIOTA, FMCSC., and CARVALHO, ABG., orgs. Tecnologias digitais na educação [online]. Campina Grande: EDUEPB, 2011. 276 p. ISBN 978-85-7879-065-3. Available from SciELO Books $<$ http://books.scielo.org $>$.

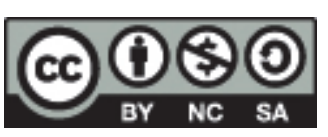

All the contents of this work, except where otherwise noted, is licensed under a Creative Commons Attribution-Non Commercial-ShareAlike 3.0 Unported.

Todo o conteúdo deste trabalho, exceto quando houver ressalva, é publicado sob a licença Creative Commons Atribuição Uso Não Comercial - Partilha nos Mesmos Termos 3.0 Não adaptada.

Todo el contenido de esta obra, excepto donde se indique lo contrario, está bajo licencia de la licencia Creative Commons Reconocimento-NoComercial-CompartirIgual 3.0 Unported. 


\title{
As novas tecnologias da informação e comunicação na perspectiva do ensino de Geografia
}

\author{
Daniel de Brito Ricarte \\ UEPB - Campina Grande, Paraíba \\ dbricarte@gmail.com \\ Ana Beatriz Gomes de Carvalho \\ UEPB - Campina Grande, Paraíba \\ anabeatrizuepb@gmail.com
}

\section{Introdução}

A revolução técnico-científica-informacional, oriunda dos adventos contemporâneos das NTICs (Novas Tecnologias da Informação e Comunicação), é vivenciada atualmente através de inovações e tecnologias que trazem o conforto, comodidade e bem estar social, porém ainda de forma desigual.

Embora muitas dessas tecnologias venham ganhando notoriedade no cenário da sociedade de consumo, elas ainda não se popularizaram pela falta de informação e disponibilidade financeira das classes sociais menos favorecidas economicamente, como também pela ausência de investimentos na logística estrutural, na qualificação profissional ou mesmo pela resistência de alguns 
profissionais da educação que ainda possuem aversão ao novo e por isso ainda utilizam práticas didáticas um pouco ultrapassadas, visto que muitos professores ainda sintetizam uma aula pautada na descrição e na memorização de conceitos, que são somente utilizados na prova escrita e depois esquecidos pelos alunos em sua vida prática, não os levando a pensar, refletir e agir, através da consciência crítica e de ações cidadãs que elevem a qualidade de vida da sociedade.

Em decorrência de tais fatos, os professores de geografia, como cientistas sociais e educadores que interagem de forma histórica e dialética nos acontecimentos do mundo globalizado, são convocados a pesquisar, interagir, questionar, criticar e finalmente criar perspectivas sobre a estrutura e o contexto da inclusão digital voltada ao uso das NTICs no ensino da Geografia, de modo que este ensino se modifique para atender ao paradigma societal contemporâneo, através do suporte das ferramentas didático-tecnológicas, objetivando tornar a aula de Geografia mais dinâmica, interessante e interativa ao aluno.

Portanto, objetiva-se neste trabalho analisar as Novas Tecnologias da Informação e Comunicação (NTICs) na perspectiva do ensino da Geografia, através da pesquisa e análise das mesmas voltadas aos propósitos da Geografia crítica e da sua divulgação, através da criação do portal digital Geografia Online (www.geografiaonline.net), um site didático-digital que visa promover e socializar digitalmente o uso das NTICs, junto aos professores e alunos de Geografia em consonância com as transformações sócio-ambientais decorrentes da revolução técnico-científica-informacional.

\section{A aparência e organização do Portal}

Depois de inúmeras pesquisas na internet, observou-se que a quantidade de sites destinados ou relacionados com o ensino da Geografia, ainda são numericamente inexpressivos. Os 
poucos que foram encontrados apresentam conteúdos destinados ao tratamento de assuntos específicos: cartografia, geologia, geomorfologia, manejo agrícola, sensoriamento remoto, etc. Mesmo assim, nenhum deles trata da formação dos professores especificamente, no sentido de promover a socialização digital das NTICs. A partir desta análise, foi desenvolvida e apresentada a proposta de construção do portal Geografia Online.

O portal Geografia Online possui os seguintes espaços virtuais: artigos - onde são encontrados artigos educacionais, textos literários e não literários que tratam das NTICs e das experiências, relatos e projetos voltados ao ensino da Geografia. Estes artigos são divulgados por educadores e interessados pelas temáticas do portal; tutoriais - contém apostilas como, por exemplo, a do CMAP TOOLS, um programa para a elaboração de mapas conceituais; serviços - nesta área do portal são disponibilizadas informações e sugestões didáticas quanto ao uso dos serviços web, orientando os professores quanto a melhor forma de utilização dos recursos da internet na sala de aula ou no ensino a distância, tais como: fóruns, podcasts, GOOGLE MAPS, etc; softwares - são apresentados alguns softwares que podem ser utilizados para o ensino da Geografia de forma didática utilizando a internet; fórum - oferece informações e hiperlinks aos professores de Geografia, alunos e interessados na comunidade Geografia Online existente no ORKUT, visando a contribuição coletiva, integração interativa e a otimização do site, além do debate crítico, da apresentação de projetos e de experiências desenvolvidos no ensino da Geografia; vídeos - são disponibilizados vídeos educativos sobre serviços web, softwares educacionais e conteúdos voltados ao ensino da Geografia e de práticas educativas de uma forma geral; links - área do portal que possibilita a divulgação de sites relacionados com as Novas Tecnologias da Informação e Comunicação; contato - contém os e-mails do criador e dos colaboradores do portal Geografia Online, para que os educadores possam entrar em contato enviando dúvidas, críticas e sugestões para o 
constante desenvolvimento deste projeto. Os espaços virtuais do portal Geografia Online podem ser vistos na Figura 01.

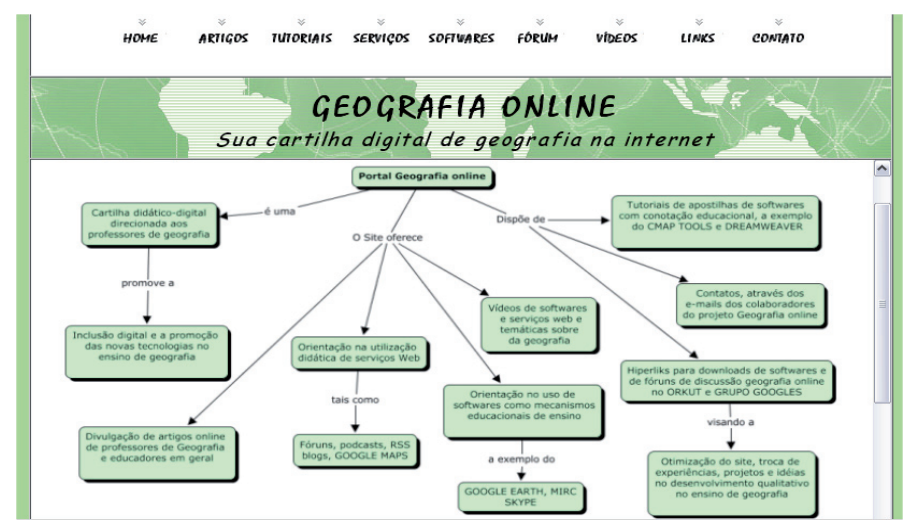

Figura 01 - Interface Gráfica da página inicial do portal Geografia Online.

Serão detalhadas a seguir, algumas das Novas Tecnologias da Informação e Comunicação que compõem este portal, incluindo a sua definição, possibilidades e perspectivas pedagógicas destes recursos.

\section{Os fóruns e seus mecanismos didáticos de comunicabilidade na aprendizagem}

Como o próprio nome sugere, os fóruns são espaços virtuais coletivos, destinados ao debate de temas, ideias e opiniões variadas sobre os mais diversificados assuntos. No que se refere às praticas didáticas, os fóruns são ferramentas assíncronas, isto é, o usuário acessa de acordo com a disponibilidade do seu horário, proporcionando a interatividade e conforto, diante das atribuições e responsabilidades do dia-a-dia. 
Há vários tipos de fóruns presentes na internet: fóruns sobre informática, música, TV, livros, fóruns de universidades, editoras, etc. Um dos mais famosos, heterogêneo e popular no Brasil é o ORKUT. Nele os fóruns são criados dentro de comunidades com temas específicos, tais como: cidades, debate sobre política, aspectos profissionais de uma mesma área, empresa específica, grupos de educadores, enfim o uso do ORKUT se faz de acordo com o interesse de cada indivíduo, que pode variar de acordo com a sua formação e seus planos. Desse modo, Starobinas (2007), mostra que:

O uso que se faz do ORKUT depende do interesse pessoal de cada internauta e da orientação específica que ele venha a ter. $\mathrm{O}$ educador interessado em utilizá-lo precisará organizar detalhadamente a sua estratégia; para evitar a atividades excessivamente dispersivas. Deixando clara, as regras do jogo, o ORKUT pode ser um espaço de expressão e de intercâmbio de informações bastante rico em atividades educacionais (STAROBINAS, 2007, p.190).

Estas comunidades podem ser moderadas, ou seja, o participante delas somente se fará presente nos debates, mediante a aprovação dos moderadores das comunidades. Depois de efetuado o cadastro no ORKUT, um professor de Geografia pode por exemplo criar uma comunidade específica das suas disciplinas, séries ou turmas, facilitando aos alunos tirarem dúvidas, como também a explanação de ideias, debates sobre assuntos ou temáticas importantes da aula, também permite aos alunos sugerirem sites de pesquisa ou discutirem algum tema que tenha sido abordado, ou seja, os fóruns levam os alunos a debater, se informar, participar, pensar, e emitir a sua opinião sobre uma questão levantada. A interface gráfica do ORKUT pode ser vista na Figura 02. 


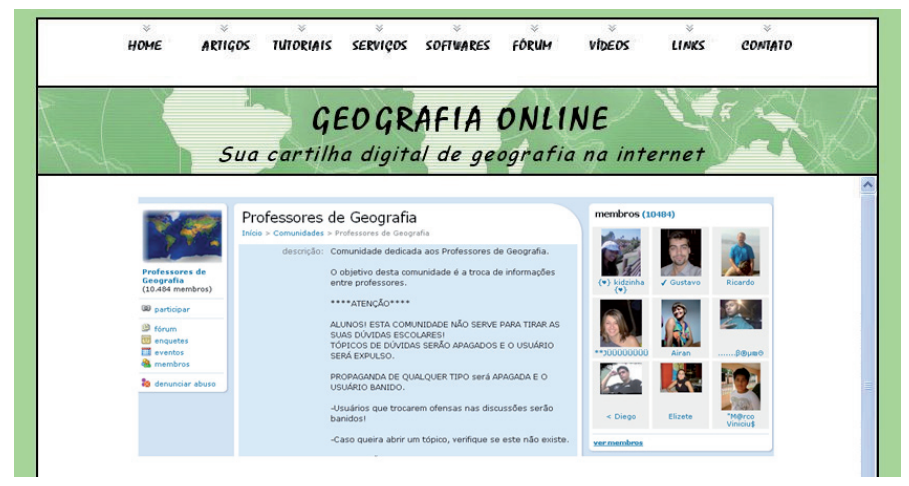

Figura 02 - Comunidade de professores de Geografia no ORKUT

Outra forma interessante de se promover a comunicabilidade virtual, porém de forma síncrona em tempo real, são as salas de papo virtuais, os chamados chats. Neles os alunos podem conversar e estreitar a sua convivência interpessoal através das salas de bate-papo que promovem a socialização e uma maior interação das relações humanas.

\section{0 uso dos mapas conceituais no ensino de Geografia}

A transmissão e a aprendizagem de distintos conhecimentos na construção do pensamento, traz ao educador a necessidade de aplicar novas técnicas didáticas que facilitar o desenvolvimento cognitivo dos seus alunos, onde o nível de aprendizagem será crucial para a aquisição dos conhecimentos no processo de ensino-aprendizagem. Diante disso, além da leitura e interpretação de textos, figuras, entre outros recursos didáticos, deve-se levar em conta também a importância da explanação crítica do professor, que deve ser auxiliada por recursos didático-tecnológicos criativos, utilizando imagens e símbolos que proporcionem uma interação construtivista do aluno que ao visualizar uma imagem, possa interligar as ideias, representando a construção associativa do 
conhecimento. A seguir, será apresentado na Figura 03 um exemplo de mapa conceitual que pode ser utilizado pelo professor no processo de ensino-aprendizagem em sala de aula.

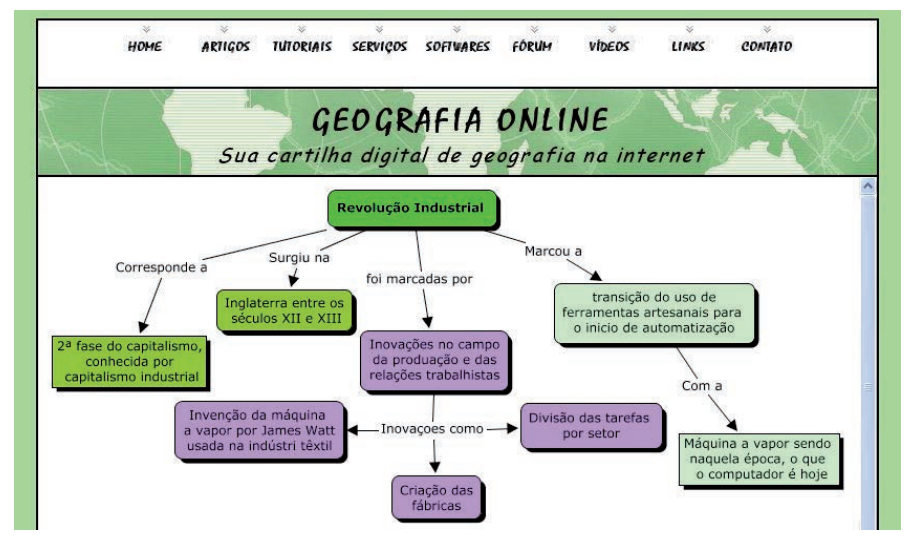

Figura 03 - Mapa conceitual da revolução industrial.

Os mapas conceituais constituem-se ferramentas indispensáveis para a construção hierárquica e associativa do conhecimento nas várias áreas do conhecimento, através de representações gráficas semelhantes aos diagramas das redes semânticas, onde o professor e o aluno podem construir seu conhecimento e representá-lo por diagramas e palavras conectadas por frases de ligação, funcionando como mecanismos na conexão das ideias no processo de aprendizagem colaborativa entre o educador e o aluno. Salienta Campos (2003, p. 1), "Este é o mecanismo de aprendizagem colaborativa onde o professor agiu como o par mais capaz de seu aluno". Neste momento o professor é o orientador, assim como o colega que conhece melhor a temática, favorecendo o crescimento e a construção do conhecimento. Assim, o professor é como um coordenador do ato de aprender que conhece melhor os conteúdos, favorecendo o crescimento e a construção da aprendizagem. Um conhecimento conceitual que na verdade é um texto que não é não linear, mas 
sim multilinear, possuindo uma dinâmica que permite ao aluno construir os conhecimentos adquiridos anteriormente, bem como as novas ideias aprendidas na sala de aula. A esse respeito, Okada (2007, p. 116) afirma que:

O texto, por ser linear, dificulta as conexões de idéias e informações. Os mapas, por terem uma estrutura gráfica, permitem que conceitos sejam registrados através de palavras chaves e relações estabelecidas através de linhas. Desse modo, a interface gráfica de um mapa torna-se mais fácil para trazer conceitos cujas relações podem ser estabelecidas sem a ordem predefinida e de modo multi-linear.

Os mapas conceituais constituem uma forma de ensino dinâmico que pode motivar a compreensão de velhos e novos conceitos, pois a medida que a aluno representa seus conhecimentos de uma forma sequencial e organizada, novas ideias surgem e outros conhecimentos são relacionados à estrutura cognitiva de sua percepção intelectual, servindo de base para essa conceituação, gerando o crescimento e o domínio das informações desenvolvidas nas novas perspectivas de conhecimentos inter-relacionados e interdisciplinares.

\section{A comunicabilidade interativa e educativa do SKYPE}

O SKYPE é um programa gratuito que permite a comunicação via áudio, através da conexão VOIP (Voz sobre IP), realizando chamadas telefônicas e de videoconferência, sem nenhum custo aos usuários conectados a este software. Ele também permite que com um baixíssimo custo, o usuário possa realizar ligações para telefones fixos e celulares locais, interurbanos e internacionais. 
A qualidade do áudio é excelente, além de possuir uma agradável interface e funcionalidades simples de serem utilizadas. $O$ SKYPE dá suporte a videoconferência simultânea para pelo menos quatro pessoas com a utilização de webcam em tempo real.

Segundo a enciclopédia digital WIKIPÉDIA, “o SKYPE está disponível em 27 idiomas e é utilizado em quase todos os países”, com isso ele vem proporcionando a interatividade entre milhões de pessoas espalhadas pelo planeta. Nele é possível enviar arquivos, criar salas de bate papo para até 100 participantes. Os requisitos para a comunicação de áudio pela internet são: ter a disposição um computador que possua uma placa de som, um microfone, um fone de ouvido e caixas de som, além de estar conectado a internet.

Em termos educativos, o SKYPE vem sendo bem sucedido no ensino de idiomas, como também no intercâmbio entre professores e alunos do Brasil e de outros países que desejam aperfeiçoar os seus conhecimentos. No ensino da Geografia, o SKYPE pode ser utilizado para que o professor possa tirar dúvidas dos seus alunos, proporcionando debates de conteúdos e a realização de tarefas e trabalhos em equipe com comodidade e conforto, diminuindo o tempo gasto nestas atividades.

Atualmente, o SKYPE vem ganhando notoriedade na EAD (Educação a distância) através do TALKANDWHITE, um aplicativo educacional complementar do SKYPE, que foi desenvolvido no Brasil, mais especificamente em Santa Catarina, de acordo com o Portal Fator Brasil (2008),

Reconhecido pelo Ministério da Educação (MEC), o software foi desenvolvido em Santa Catarina, já possui milhões de usuários no exterior e hoje está conquistando também o mercado nacional de Ensino a Distância. Idealizado para uso em webconferências, a ferramenta brasileira já ultrapassou a marca de 1 
milhão de downloads desde o lançamento, há pouco mais de um ano, e ocupa atualmente a segunda posição no ranking do Skype, com média de 5 mil a 6 mil novos usuários por dia. Traduzido em 27 idiomas, o software encontrou na Europa, na Ásia e no Pacífico o principal mercado consumidor. Porém, com o crescimento da rede de Ensino a Distância no Brasil, o software, que é o único brasileiro reconhecido como aplicativo Premium no Skype, está conquistando também educadores e alunos brasileiros (PORTAL FATOR BRASIL, 2008).

Essa ferramenta permite a comunicação entre os alunos, via voz como também pela utilização e construção interativa de textos e imagens em tempo real, sendo possível que até dez pessoas trabalhem em um mesmo documento, permitindo que várias pessoas possam escrever, grifar, desenhar, apagar, fazer anotações e construir coletivamente textos virtuais que serão arquivados, impressos na tela ou papel e acessados quando o aluno desejar. Os alunos podem discutir e construir o conhecimento em tempo real, podendo expressar as suas emoções, através dos gestos e expressões faciais que o software disponibiliza. Essa ferramenta vem sendo bem utilizada do ensino de idiomas, pois trabalha dentro das quatro habilidades: ler, falar ouvir e escrever. A seguir, na Figura 04 será apresentada a ferramenta TALKANDWHITE do SKYPE. 


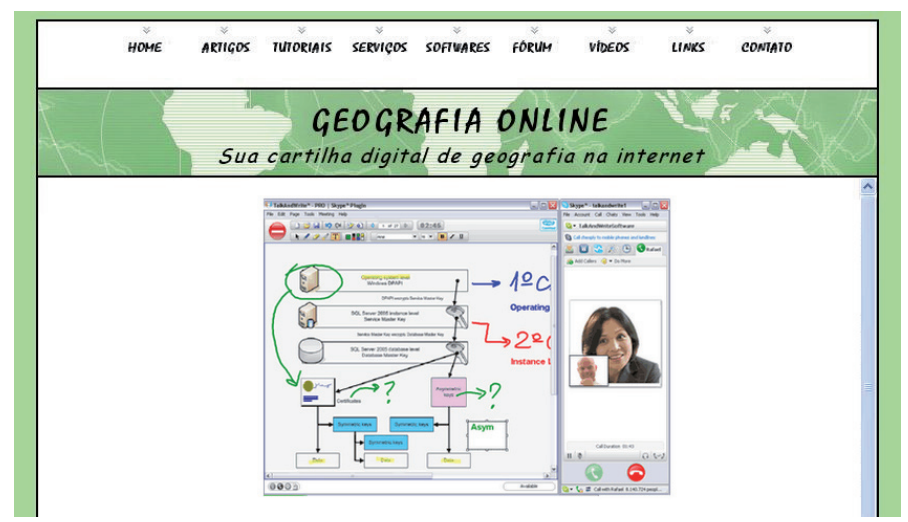

Figura 04 - Visualização da ferramenta TALKANDWHITE do SKYPE.

Sobre a óptica das práticas didáticas do ensino da Geografia, o SKYPE munido do aplicativo TALKANDWHITE, traz a perspectiva de uma melhor utilização em várias modalidades de ensino, especialmente para a Educação a Distância da Geografia, podendo ser manejada para a leitura, interpretação e análise de mapas cartográficos, fotos de satélite dos tipos de vegetação, relevo e análise de imagens de dados sobre o desmatamento. Além disso, serve para a construção simultânea e coletiva de artigos, textos e trabalhos em equipe ou mesmo debate entre os alunos e professores, quanto aos conteúdos ou dúvidas que possam por ventura surgir na aula, melhorando a perspectiva do ensino da Geografia por meio da Educação a Distância. A esse respeito, Starobinas, (2007, p. 186):

O ensino à distância é uma modalidade de ação pedagógica que pode priorizar tanto a transmissão de conteúdo de forma impessoal, quanto o acompanhamento dos estatutos de cada aluno, ou ainda utilizar-se da interação entre os participantes para catalizar o processo de aprendizagem. 
O fato de o SKYPE ser um programa de grande difusão mundial e possuir uma interface gráfica atrativa, sendo fácil de ser manuseado, facilita a sua utilização para diversos tipos de usuários. Em relação ao aplicativo complementar TALKANDWHITE, a instituição de ensino ou o professor devem adquirir a licença do software para terem acesso a versão $\mathrm{PRO}$, enquanto os alunos poderão utilizar a versão básica que é gratuita. Não é surpresa que em outros países essa ferramenta vem sendo adquirida e tornando-se suporte para uma aprendizagem dinâmica no contexto das Novas Tecnologias da Informação e Comunicação, por ser um mecanismo educativo atrativo, motivante, eficiente e colaborativo. Aos poucos, o Ministério da Educação vem elevando os investimentos na logística educacional em seus vários níveis de ensino, quem sabe essa ferramenta possa fazer parte da tão falada "revolução na educação brasileira".

\section{Os vídeos online no ensino de Geografia}

Os sites de acesso a vídeos online, principalmente o YOUTUBE e em segundo plano o GOOGLE VÍDEO são espaços virtuais em que se pode assistir a um vídeo pela internet sem a necessidade de baixar o vídeo. Este ambiente virtual possibilita a busca pelo vídeo desejado, além da integração entre os usuários que podem fazer comentários acerca dos vídeos.

Hoje, percebe-se que a maioria das câmaras digitais e dos celulares têm suporte para a realização de filmagens caseiras. Estes objetos tecnológicos vêm se tornando cada vez mais populares entre os jovens, adolescentes e adultos de várias partes do Brasil, inclusive das classes sociais menos favorecidas.

Os sites de exibição de vídeo tornaram-se bastante procurados na atualidade, diante da necessidade das pessoas de captar e guardar os momentos marcantes das suas vidas, além de compartilhar com outras pessoas as suas produções que podem ser: trabalhos pessoais, 
atividades artísticas e musicais, momentos históricos, paisagens da sua região, etc. A esse respeito, Moran (1997), verifica que:

O vídeo é também escrita. Os textos, legendas, citações aparecem cada vez mais na tela, principalmente nas traduções (legendas de filmes) e nas entrevistas com estrangeiros. A escrita na tela hoje é fácil através do gerador de caracteres, que permite colocar na tela textos coloridos, de vários tamanhos e com rapidez, fixando ainda mais a significação atribuída à narrativa falada (MORAN,1997. p.1).

No YOUTUBE ou no GOOGLE VÍDEOS os alunos podem criar vídeos "caseiros" sobre os mais diversos temas dos conteúdos da Geografia, por exemplo: vídeos que tratem dos aspectos sociais do seu bairro, das características das atividades econômicas da sua cidade, dos momentos políticos do seu município, de uma feira de ciências realizada em sua escola, etc. Tudo isso pode ser hospedado no YOUTUBE, tornando essa produção acessível aos colegas e a própria sociedade de uma maneira geral.

O interessante é que os alunos individualmente ou em grupo podem se tornar exploradores do seu espaço, observando, descobrindo e analisando as diversidades socioambientais que a sala de sala não trazia às suas mentes, desenvolvendo sua percepção social sobre a realidade em que vivem, assim tornando cidadãos críticos e ativos em termos de ideias e ações viáveis que contribuam para a percepção dos problemas de sua comunidade, gerando soluções criativas para a melhoria do ambiente em que vive.

Os professores e os alunos de Geografia ou de outras disciplinas podem fazer comentários sobre os vídeos produzidos, discutindo a temática abordada, gerando opiniões, ideias e debates com elucidação que beneficie a população que faz parte desse cenário e que tem direito a informação, politização e educação de qualidade. 


\section{Conclusão}

Este estudo prepositivo acerca das novas tecnologias no ensino de Geografia foi bastante gratificante, não somente pelo ato de pesquisar, analisar, refletir, indagar e interagir sobre essas ferramentas didático-tecnológicas de alta relevância na melhoria do ensino e das práticas didáticas dos professores de Geografia, mas também na contribuição efetiva para a maior riqueza que um povo pode conquistar, que é ter uma educação de qualidade. Hoje, a educação no país ainda é bastante necessitada de investimentos públicos, recursos logísticos e humanos que promovam a construção consciente de valores éticos, empáticos e sustentáveis. Afinal, a verdadeira grandeza de um povo é o ato de aprender, apreender e servir ao engrandecimento evolutivo do ser humano.

Neste trabalho foram analisadas algumas das Novas Tecnologias da Informação e Comunicação (NTICs) que fossem viáveis como suporte na aprendizagem do ensino da Geografia de forma dinâmica, atraente e interessante aos alunos. Além disso, foram sugeridas atividades e formas de trabalhar a utilização desses mecanismos no ensino de Geografia, sendo desenvolvido o portal didático Geografia online, uma cartilha digital que disponibiliza um leque de serviços WEB e softwares de funcionalidade educacional que tem a finalidade de socializar digitalmente os educadores de Geografia, quanto a utilização interativa e construtiva das Novas Tecnologias da Informação e Comunicação.

O portal Geografia online contará com a cooperação, participação, divulgação de textos e artigos de professores de Geografia e de profissionais de áreas científicas voltadas para a qualidade educacional. Assim, o site disponibilizará fóruns de discussão na comunidade do ORKUT, visando uma constante troca de experiência, conhecimentos e desenvolvimento didático de um ensino dinâmico, motivador e crítico da Geografia. Contudo, a melhoria dessas ferramentas dependerá essencialmente das práticas 
educativas coordenadas pelo professor, além da sua criatividade e criticidade em construir uma aprendizagem que leve o aluno a ter vontade de participar, pensar e interagir no processo de desenvolvimento das suas habilidades voltadas para o bem estar social.

Fora isso, o presente trabalho trata da novas abordagens epistemológicas, através de críticas, pesquisas, debates e a busca incessante da solução das questões sociais que fortaleçam a escola, o ensino de Geografia e revitalização da cidadania na superação de desafios e na construção de um planeta menos desequilibrado socialmente, através de soluções derradeiras que estejam dispostas ao sucesso promissor das gerações vindouras, na promoção de ações cooperativas que favoreçam o desenvolvimento econômico, tecnológico e social dos países subdesenvolvidos e em desenvolvimento, tão necessitados de um crescimento econômico equilibrado e de uma distribuição de riquezas mais equitativa, não somente em relação à renda e ao Produto Interno Bruto (PIB), mas também buscando um maior volume de investimentos financeiros que possam promover à inclusão social, o acesso à informação e a consolidação de uma educação voltada a formação intelectual de uma sociedade crítica.

\section{Referências}

CAMPOS, G. H. B. Mapas conceituais e EAD. 2003. Disponível em: $<$ http://www.timaster.com.br/revista/colunistas/ler_colunas_emp. asp?cod=730>. Acesso em 16 de nov. 2008.

OKADA, A. L. Mapas conceituais em projetos e atividades pedagógicas. In: Moraes, U. C. Tecnologia Educacional e Aprendizagem: o uso dos recursos digitais. 2. ed. São Paulo: Livro pronto. p. 115 a 127.

MORAN, J. M. O vídeo na sala de aula. 1997. Disponível em: <http:// www.eca.usp.br/prof/moran/vidsal.htm> Acesso em 15 de Nov. 2008. 
OKADA, A. L. Mapas Conceituais em projetos e atividades pedagógicas. In: MORAES, U. C. Tecnologia educacional e aprendizagem: o uso dos recursos digitais. São Paulo: Livro Pronto, 2007. p. 115 - 127.

PORTAL FATOR BRASIL. Tecnologia brasileira ganha espaço na educação a distância. 2008. Disponível em: <www.revistafatorbrasil. com.br/ver_noticia.php?not=28980 >. Acesso em: 16 de Nov. 2008.

STAROBINAS, L. Interação de professores em fóruns eletrônicos: um estudo de caso do programa Educar na Sociedade da Informação. 2008. Tese (Doutorado em Educação) - Universidade de São Paulo, São Paulo, 2008.

STRATOBINAS, L. 0 caminho das pedras: colaboração em redes digitais. In: MORAES, U. C. Tecnologia educacional e aprendizagem. São Paulo: Livro Pronto, 2007. p. 183 - 200.

\section{(Footnotes)}

${ }^{1}$ Esta aula faz parte da $2^{\mathrm{a}}$ edição juntamente com as aulas 09 e 14 . Não apresentam sub-temas. 